\title{
A Educação à Distância e a Função do professor
}

\author{
Caroline Maria Tavares de Sampaio ${ }^{1}$; Demetrius Oliveira Tahim ${ }^{2}$
}

\begin{abstract}
Resumo: Este artigo tem como tema refletir sobre a postura que o professor de Educação à Distância (EAD) deve assumir. O seu objetivo é entender melhor o processo de ensino e aprendizagem na EAD, procurando encontrar a posição adequada para o professor. $\mathrm{O}$ trabalho se justifica pelo crescente desenvolvimento que este modelo educacional vem vivenciando. De cunho bibliográfico, este trabalho foi buscar respaldo nas pesquisas de autores como: Moran, Masetto e Behrens (2014) e Peixoto e Silveira (2014), entre outros. Portanto, para construção desse trabalho, primeiramente, foram feitas três conceituações de EAD. Depois, uma retrospectiva histórica da EAD foi descrita. Em seguida, o discente foi citado como sendo o principal elemento da EAD. Então, foi lembrada a importância de se construir laços virtuais, para que resultados positivos possam ser confirmados. Por fim, os objetivos do professor de EAD foram elencados. Posteriormente, foram citadas algumas mudanças na EAD, como consequência da utilização cada vez mais intensa da internet. Só então, a interatividade entre professor e aluno, foi lembrada como fator essencial para o sucesso de um curso à distância. Finalmente, a postura ideal para o professor de EAD foi detalhada. Esta obra foi executada com a pretensão de contribuir para que a EAD seja devidamente analisada e aprimorada.
\end{abstract}

Palavras chave: Educação à Distância (EAD); Professor; Laços Virtuais.

\section{Distance learning and the teacher's role}

\begin{abstract}
This article focuses reflect on the position that the teacher Distance Learning (ODL) should take. Its goal is to better understand the process of teaching and learning in distance education, seeking to find the proper position for the teacher. The work is justified by the increasing development of this educational model has experienced. Bibliographic nature, this work was to seek support in the research of authors such as: Moran, Masetto and Behrens (2014) and Peixoto and Silveira (2014), among others. Therefore, construction of this work, first, were made three conceptualizations of EAD. Then, a historical retrospective of the EAD has been described. Then the student was cited as the main element of ODL. So it was recalled the importance of building virtual links, that positive results can be confirmed. Finally, the ODL teacher's objectives were listed. They were later cited some changes in the EAD, as a result of using increasingly intense the internet. Only then, the interaction between teacher and student, was remembered as a key factor for the success of a distance learning course. Finally, the ideal posture for the teacher of EAD was detailed. This work was performed with the intention to contribute to the EAD is properly analyzed and improved.
\end{abstract}

Keywords: Distance Education ( EAD); Teacher; Virtual ties.

\section{Introdução}

Este trabalho discorrerá sobre a função que o professor de Educação à Distância (EAD) deve assumir. Serão elencadas, primeiramente, as três maneiras de se conceituar a EAD, dependendo da visão de mundo. Então, uma retrospectiva histórica da EAD será feita. Em seguida, falar-se-á sobre o aluno como sendo o elemento principal deste modelo de educação.

\footnotetext{
${ }^{1}$ Licenciada em Letras, mestranda em Educação e pós-graduada em Linguística (FAFIRE-Recife), lecionando Língua Portuguesa. Mestranda em Educação pela Anne Sullivan University. E-mail: carolsampaio80@ gmail.com;

${ }^{2}$ Filósofo pela Universidade Estadual do Ceará. Doutorando em Filosofia pela Universidade Federal do ceará. Especialista em Educação à Distância e Estudos Clássicos.
} 
Mais adiante, será ressaltada a grande importância de se construir laços virtuais para que o aprendizado seja significativo em um curso à distância. Por fim, serão expostos os reais objetivos de um professor de EAD. Posteriormente, serão mencionadas algumas mudanças na EAD, depois da popularização da internet. A interatividade entre professor e aluno será citada como fator essencial para o sucesso de um curso à distância. E finalmente, a postura ideal de um professor de EAD será descrita.

Esta pesquisa se faz necessária para que os profissionais de cursos à distância possam repensar as suas atitudes a fim de obterem melhores resultados. Além disso, as pessoas em geral poderão entender melhor como funciona este modelo de ensino.

Este artigo foi organizado a partir de pesquisas bibliográficas com estudos e análises em autores como: Moran, Masetto e Behrens (2014), Peixoto e Silveira (2014), entre outros. Serão apresentados os pensamentos de alguns autores e, em seguida, serão feitos comentários a cerca de cada posicionamento. Então, a partir de comparações entre os pontos de vista de cada escritor, reflexões serão feitas a respeito da função do professor de Educação à Distância (EAD).

Com este trabalho, pretende-se refletir sobre a postura ideal que um professor de Educação à Distância (EAD) deve assumir. Em um mundo onde as relações virtuais estão se propagando aos montes, com a internet dominando cada vez mais, uma análise sobre a EAD e a função do professor neste modelo educacional torna-se bastante útil.

A princípio, a Educação à Distância (EAD) será conceituada de três formas distintas. $\mathrm{O}$ planejamento será lembrado como algo essencial para o professor de EAD. Depois, será feita uma retrospectiva histórica da EAD, evidenciando-se o seu surgimento bem anterior ao surgimento da internet. Então, o aluno será descrito como o principal elemento da EAD. Em seguida, a grande importância de se construir laços virtuais entre professor e aluno, será lembrada.

Por fim, a posição que o professor de Educação à Distância (EAD) deve assumir, será analisada. Então, serão descritos os objetivos do docente na EAD. Posteriormente, serão numeradas algumas mudanças que aconteceram na EAD com a grande utilização da internet. Em seguida, será evidenciada a grande importância da interatividade entre professor e aluno para a eficácia do aprendizado à distância. Depois, a importância das Tecnologias de 
Id on Line Revista Multidisciplinar e de Psicologia

Id on Line Multidisciplinary and Psycology Journal

Informação e Comunicação (TICs) para o estabelecimento da interação entre as partes, será lembrada. E finalmente, será especificada a postura ideal que um professor de EAD deve assumir para que o seu trabalho seja produtivo e eficaz.

\title{
A Educação à Distância
}

Pode-se conceituar a Educação à Distância (EAD), a princípio, apenas evidenciando-se as diferenças que existem entre ela e a educação presencial. Mais adiante, o conceito deste novo modelo de educação pode basear-se na possibilidade de se transmitir uma grande quantidade de informação para um grande número de pessoas, num curto espaço de tempo. Uma terceira conceituação para esta nova modalidade de ensino poderá ressaltar a forma de comunicação entre professores e alunos, descrevendo-se como acontece o contato entre as partes.

A Educação à distância (EAD) está cada vez mais à procura de novos métodos que estimulem as pessoas a irem atrás do conhecimento. A este respeito, é importante acrescentar que:

\begin{abstract}
No que diz respeito à Educação, uma área que vem se desenvolvendo e tomando notoriedade nos processos de formação é a EAD - Educação a Distância, que de forma acelerada, vem revolucionando a maneira como as pessoas buscam o conhecimento e o saber. Tais mudanças, no meio acadêmico e empresarial, têm dado resultados positivos exigindo que sejam repensados, ou mesmo, reinventados novas formas de ensinar, novas metodologias, novos instrumentos de transmissão e novos meios tecnológicos para mediar os conhecimentos. Neste sentido, pesquisadores em todo mundo avançam, com o intento de melhor explicar o fenômeno que hoje revoluciona a educação, a Educação a Distância (EAD). (PEIXOTO e SILVEIRA, 2014, p. 15)
\end{abstract}

O desenvolvimento das novas tecnologias digitais está contribuindo bastante para que sejam descobertas novas maneiras de ensino-aprendizagem. A busca por uma aprendizagem mais efetiva e dinâmica muito está cooperando para que a Educação à Distância (EAD) possa ter sucesso. Pois, para que a EAD consiga bons resultados é preciso organização e foco. O planejamento é vital para esta modalidade de ensino. Não se pode conceber uma aula, na EAD, sem planejamento. Já na educação presencial uma aula pode até acontecer sem planejamento.

Pode até parecer que a Educação à Distância (EAD) teve início com o surgimento da internet, mas quando se para pra pensar sobre a retrospectiva histórica desta modalidade de 
ensino e aprendizagem, tanto no Brasil como no mundo, percebe-se claramente que a modalidade em questão teve início bem antes do surgimento da internet. De acordo com o exposto acima, é conveniente declarar:

\begin{abstract}
Em síntese, sobre o histórico da EAD no mundo inteiro e no Brasil, é possível se falar na crescente dinâmica em relação às etapas que foram vencidas em pouco tempo, atingindo milhares de pessoas. De acordo com Moore (2008), a primeira etapa se fez por correspondência, depois por transmissão por rádio e por televisão, em seguida, se conheceu a implantação da Universidade Aberta, depois as teleconferências até que alcançamos o sistema internet/web. (apud cit PEIXOTO e SILVEIRA, 2014, p. 26)
\end{abstract}

Com o advento da internet, a Educação à Distância (EAD) vem tornando-se cada vez mais eficaz. Pois, a internet facilita muito o contato entre professor e alunos, além de disponibilizar um número ilimitado de informações. Porém, para que este número incontável de informações seja bem administrado, é imprescindível que o internauta se preocupe em filtrar os dados encontrados. Pois, pode-se encontrar neste recurso informações das mais pobres às mais brilhantes. Sendo assim, fica claro que não é qualquer curso à distância que irá formar um aluno. Para que a formação do discente aconteça de fato, será necessário que se adeque as ferramentas disponíveis com a proposta do curso. Neste sentido, é importante entender que:

\footnotetext{
Um dos grandes desafios para o educador é ajudar a tornar a informação significativa, a escolher as informações verdadeiramente importantes entre tantas possibilidades, a compreendê-las de forma cada vez mais abrangente e profunda e a torná-las parte do nosso referencial. Aprendemos melhor quando vivenciamos, experimentamos, sentimos. Aprendemos quando fazemos relação, estabelecemos vínculos, laços, entre o que estava solto, caótico, disperso, integrando-o em um novo contexto, dando-lhe significado, encontrando um novo sentido. (MORAN, MASETTO e BEHRENS, 2014, p. 28)
}

Todo curso à distância pode atingir uma quantidade industrial de alunos, mas para que o curso seja realmente bom, não se pode esquecer da qualidade das informações que serão veiculadas. Para um aluno da Educação à Distância (EAD) exige-se a maturidade de entender que nem todas as informações encontradas na internet são seguras. Saber selecionar as informações encontradas é algo indispensável para o progresso deste discente.

A Educação à Distância (EAD) consiste numa maneira distinta de se construir o aprendizado. Diferente da educação presencial, na EAD não existe contato direto entre professor e aluno. Sendo assim, esta modalidade de ensino exige do discente uma responsabilidade e organização bem mais consistentes. A comparação entre essas duas 
modalidades de ensino é um equívoco que não pode ser feito, visto que a aprendizagem acontece de acordo com o estilo de ensino. Sobre este assunto, pode-se ressaltar que:

O processo de ensino-aprendizagem a distância envolve vários elementos que necessitam estar em sincronia e harmonia para que essa modalidade favoreça de fato a aprendizagem, porém não podemos negar que o principal desses elementos seja o aluno. É para ele e por ele que, a produção de conteúdo, o roteiro pedagógico e a administração de qualquer atividade a distância são desenvolvidos. Estas atividades, para que obtenham sucesso, precisam necessariamente ser motivadoras, criativas e devem acontecer de forma interativa. (PEIXOTO e SILVEIRA, 2014, p. 16)

Para que a Educação à Distância (EAD) tenha bons resultados é necessário se construir laços virtuais para se estar juntos à distância. Uma vez que, neste tipo de educação, estar sozinho não dá. Justamente por não haver o contato direto entre o professor e o aluno, as ferramentas de interação da EAD devem ser suficientes para que o aluno nunca se sinta sozinho no processo de ensino e aprendizagem.

A curiosidade é um pré-requisito essencial para o aluno da Educação à Distância (EAD). Sem o contato físico com o professor, para que o aluno adquira bons resultados e seja reconhecido, ele tem que ter interesse pelo assunto e uma vontade grande de entender tudo. No entanto, na modalidade de ensino presencial, a curiosidade não é tão exigida. Pois, na educação presencial, o professor pode usar de outras estratégias para chamar a atenção do aluno. Desta forma, pode-se dizer que o aluno é o principal elemento para que a Educação à Distância se concretize.

Algo bastante interessante e positivo na Educação à Distância (EAD) é o fato de não haver competição. Nesta modalidade educativa, cada aluno contribui com o que pode para que o conhecimento possa ser construído. Assim, todos os discentes acabam contribuindo menos ou mais. Deste modo, a sedimentação do aprendizado vai acontecendo através da ajuda de todos os estudantes. Então, a aprendizagem vai sendo construída coletivamente.

Os objetivos da Educação à Distância (EAD) são bem diferentes dos objetivos de uma Educação Presencial; até porque a construção do conhecimento acontece de maneira bem diferente, nesses dois modelos de educação. Na EAD, além de se pretender transmitir as informações específicas sobre um conteúdo para que os alunos, através de interações estabelecidas, possam transformá-las em conhecimentos, objetiva-se também capacitar o estudante a aprender a aprender e aprender a fazer. Sendo assim, um discente de EAD acaba por assumir atitudes bem mais independentes e autônomas na busca pelo conhecimento. 
Id on Line Revista Multidisciplinar e de Psicologia

Id on Line Multidisciplinary and Psycology Journal

\section{As atitudes do Professor frente a Educação à Distância}

Diferente do que se possa imaginar, na Educação à Distância existem várias maneiras de comunicação. A comunicação pode acontecer do aluno para o professor, do professor para o aluno, do professor para os alunos, de um aluno para os outros alunos. A comunicação é bidirecional tanto na educação presencial como na educação à distância.

$\mathrm{Na}$ Educação à Distância (EAD), o professor jamais pode ser visto como único protagonista. Até porque o maior peso na relação de educação à distância é o do aluno. Se não houver um aluno comprometido e em busca de conhecimento, nem um professor com todos os pré-requisitos necessários conseguirá fazer com que a aprendizagem aconteça de fato. Na EAD, a grande pressão sobre o "poder" do professor não é forte como na educação presencial. Porque o controle da vontade de aprender e do compromisso depende bem mais do aluno do que do professor.

O que acontece na Educação à Distância (EAD) é um trabalho bem mais independente e flexível, no qual o professor quer muito mais do que simplesmente transmitir conhecimentos específicos sobre determinado assunto. Mais ainda do que trazer informações confiáveis para seus alunos, o que o professor de EAD pretende é capacitá-los a aprender a aprender e aprender a fazer.

De acordo com tudo o que foi dito sobre o sistema de Educação à Distância (EAD), fica fácil entender que a posição do professor neste modelo de educação é bem mais leve. Aqui, o professor deve se preocupar em ser agradável, humilde, confiante, sempre demonstrando entusiasmo sobre a vida e sobre o assunto específico da aula. Transmitir credibilidade para os alunos é fundamental para que o aprendizado se concretize. Um professor que conseguir manter uma atitude honesta e coerente com seus pupilos, levando-os a pensar e a buscar sempre mais, acabará tendo êxito na sua tarefa de ensinar na EAD. Diante do que foi dito acima, ainda podese afirmar que:

As mudanças na educação dependem, em primeiro lugar, de termos educadores maduros intelectual e emocionalmente, pessoas curiosas, entusiasmadas, abertas, que saibam motivar e dialogar. Pessoas com as quais valha a pena entrar em contato, porque desse contato saímos enriquecidos. O educador autêntico é humilde e confiante. Mostra o que sabe e, ao mesmo tempo, está atento ao que não sabe, ao novo. Mostra para o aluno a complexidade do aprender, a nossa ignorância, as nossas dificuldades. Ensina, aprendendo a relativizar, a valorizar a diferença, a aceitar o 
provisório. Aprender é passar da incerteza a uma certeza provisória que dá lugar a novas descobertas e a novas sínteses. Os grandes educadores atraem não só pelas suas ideias, mas pelo contato pessoal. Dentro ou fora da aula, chamam a atenção. Há sempre algo surpreendente, diferente no que dizem, nas relações que estabelecem, na sua forma de olhar, de se comunicar, de agir. São um poço inesgotável de descobertas. (MORAN, MASETTO e BEHRENS, 2014, p. 25-26)

É desse professor/educador que a Educação à Distância (EAD) necessita. Um professor que fale com clareza, reforçando, através de atitudes e gestos, todas as suas palavras. Um professor equilibrado e aberto certamente proporcionará o aprendizado necessário ao aluno que se propuser a alargar seus conhecimentos de maneira virtual.

Depois do surgimento da internet e a sua crescente popularidade, pode-se perceber claramente algumas mudanças na Educação à Distância (EAD). Dentre estas mudanças, é cabível citar:

\footnotetext{
- Maior "presencialidade" digital, audiovisual, seja ao vivo, como teleaula, ou em gravação em webaula. Os modelos vencedores mostram muito mais o professor, criam vínculos com a sua imagem e a sua palavra.

- Maior flexibilidade de processos, comunicação quando necessário, equilíbrio entre o percurso pessoal e a interação grupal. Integração de ambientes formais digitais, que permitem o controle acadêmico, com ferramentas abertas, redes sociais.

- Produção digital predominante, e-books com toda a riqueza de vínculos, imagens, vídeos, conexões, mobilidade. A migração para o digital, mesmo num país com tantas contradições, é inexorável, pelo barateamento de custos, diminuição de custos com transporte, facilidade de atualização.

- Avaliação digital, nos momentos presenciais exigidos. É complicado, caro e inseguro realizar as avaliações presenciais em papel e enviá-las pelo correio para serem corrigidas na sede da instituição. Como até o momento há uma exigência legal de avaliação presencial no Brasil nos cursos superiores autorizados, a avaliação pode ser feita com provas digitais feitas em laboratório, com supervisão de tutores presenciais e programas de segurança e identificação dos alunos. Podem ser aplicadas diferentes provas, de um banco de questões, com o mesmo grau de dificuldade. (MORAN, MASETTO e BEHRENS, 2014, p. 64-65)
}

Dentre estas modificações que a Educação à Distância (EAD) vem sofrendo com o uso em larga escala da internet, ficou evidente a grande importância da figura do professor para que o discente possa atingir seus objetivos com louvor. O estabelecimento do vínculo entre professor e aluno é fator deveras importante para que os bons resultados possam ser percebidos na aprendizagem.

Outra mudança perceptível na Educação à Distância (EAD), com o uso da internet, é a grande facilidade para se estabelecer o contato entre professor e aluno, entre professor e alunos, entre um aluno e os outros alunos. A simplicidade para a comunicação na EAD, trazida pela internet, fez também com que o aprendizado dos discentes seja bastante aperfeiçoado pelas 
relações estabelecidas. Já que todos os integrantes do curso à distância poderão contribuir com o que aprenderam e ajudar uns aos outros nas suas possíveis dúvidas. Além disso, a possibilidade de conectar os integrantes do curso com maior agilidade muito contribuiu para que o controle acadêmico possa ser feito com celeridade e segurança.

Outro aspecto que foi bastante melhorado para o professor de Educação à Distância (EAD) foi as infinitas possibilidades de se expressar, a partir dos mais variados recursos digitais, como vídeos ao vivo, imagens, pesquisas online, conexões, dentre tantos outros.

Diante de tudo que foi mencionado sobre a função adequada que o professor de Educação à Distância (EAD) deve assumir, ficou claro a grande importância de um contato constante e efetivo entre o professor e o aluno. Na EAD, podem-se identificar três abordagens de ensino distintas, que são definidas baseando-se justamente no grau de interatividade estabelecida entre o professor e o aluno. Para que estas propostas de ensino à distância possam ser detalhadas, é válido adicionar:

\begin{abstract}
A interatividade é uma variável importante na EAD e sua ausência, ou presença, ou a intensidade em que ocorre servem para definir o tipo de proposta pedagógica que se quer implantar. Dessa forma, tanto é possível encontrar, no campo da EAD, propostas ainda calcadas em um modelo transmissivo de educação, como a broadcast, de baixa ou nula interatividade, como propostas voltadas para um alto grau de interatividade, denominadas de "estar junto virtual", ou ainda, formas intermediárias quanto ao grau de interação, como "a virtualização da sala de aula tradicional". (VALENTE, 2003, p. 30)
\end{abstract}

Diante do exposto acima, percebe-se claramente o antagonismo entre broadcast, que é a proposta na qual não é necessário nenhum contato entre docente e discente, e interatividade, que se materializa na proposta de "estar junto virtual". A interatividade fica bem compreendida quando o professor apresenta situações ou espaços que possibilitem ações recíprocas entre alunos ou entre professor e alunos, sendo estas ações mediadas pelas Tecnologias de Informação e Comunicação (TICs).

É perceptível que o professor de Educação à Distância (EAD) deve agir como um provocador, procurando sempre encontrar situações que sejam estimulantes para seus alunos durante o processo educativo. Para isto, o fundamental é que o professor dê voz a cada aluno, para que o conhecimento possa ser construído de forma empírica. Com este fim, o professor poderá se utilizar de várias estratégias, como oferecer informações relevantes, realizar experimentações, estimular a busca de diferentes fontes de informações, proporcionar a 
Id on Line Revista Multidisciplinar e de Psicologia

Id on Line Multidisciplinary and Psycology Journal

reflexão sobre qualquer processo ou produto, estimular a aprendizagem significativa dos discentes através da interação destes.

Para que todas essas estratégias possam ser concretizadas pelo professor de Educação à Distância (EAD) será necessário que os mecanismos de comunicação da EAD estejam todos ajustados a esta busca de interatividade avançada. Pois, algo essencial para que um curso à distância tenha qualidade é exatamente a aguçada interatividade entre professores, alunos e tutores.

O professor de Educação à Distância (EAD) deve estar sempre atento para que possa suprir todas as possíveis necessidades dos seus pupilos. Visto que uma das causas mais apontadas como sendo indicadoras de baixa qualidade dos cursos à distância é quando o curso deixa no estudante a sensação de que ele está isolado. Inclusive, essa impressão de isolamento é uma das principais causas de evasão nos cursos à distância.

Portanto, o professor de Educação à Distância (EAD) deve ter sempre como meta, fazer com que seus alunos sintam-se como integrantes de um grupo, ou seja, partes de um conjunto que procura crescer juntos. É essencial que o aluno sinta-se apoiado, amparado nas suas dúvidas. $\mathrm{O}$ estudante precisa ter a sensação de que sempre existe a quem ou ao que recorrer. Conseguindo cumprir esta finalidade, o professor certamente estará no caminho certo.

\section{Considerações Finais}

Espera-se que este trabalho venha a colaborar para que uma reflexão a respeito da Educação à Distância (EAD) possa ser feita. Pois, entender esse modelo de ensino que tanto vem se expandindo, com a popularização da internet, é algo bastante útil e necessário.

É importante que o leitor alcance a compreensão necessária sobre a função que o professor deve assumir na Educação à Distância (EAD). Entender o que compete ao professor de EAD e o que não compete já é um importante passo a ser dado, para que o vínculo se estabeleça de forma saudável e natural, entre professor e aluno.

Ainda que este estudo não tenha a pretensão de esgotar o tema, espera-se que ele possa contribuir para que se perceba quais as melhores estratégias a serem utilizadas pelos professores 
de Educação à Distância (EAD) para que estes possam alcançar resultados positivos no processo de ensino e aprendizagem à distância.

Entender que o aluno é o elemento principal da Educação à Distância (EAD) é fator essencial para que esta modalidade de ensino possa desenvolver-se de fato. Pois, na EAD, o aluno deve assumir bem mais responsabilidades, além da sua capacidade de organização ser aprimorada. É preciso perceber que este modelo de ensino exige do aluno uma independência e autonomia bem mais consistentes.

Depois de tudo, é relevante lembrar que na Educação à Distância (EAD) a interatividade entre professor e alunos é fundamental para que o conhecimento se construa. É a partir do contato virtual entre o professor e os alunos que as informações poderão ir sendo trabalhadas, para que assim, possam ser transformadas em conhecimentos.

\section{Referências}

MORAN, José Manuel; MASETTO, Marcos T.; BEHRENS, Marilda Aparecida. Novas tecnologias e mediação pedagógica. 21. ed. Campinas, SP: Papirus, 2014.

PEIXOTO, Vanessa Alessandra Cavalcanti; SILVEIRA, Daniella Santos da. Educação a Distância e Ambientes Virtuais de Aprendizagem: notas introdutórias sobre teoria e prática. Rio de Janeiro: Multifoco, 2014.

VALENTE, José Armando. Curso de Especialização em desenvolvimento de projetos pedagógicos com o uso das novas tecnologias: descrição e fundamentos. In: Educação a distância via Internet. São Paulo: AVERCAMP, 2003.

\section{Como citar este artigo (Formato ABNT):}

SAMPAIO, C.M.T.; TAHIM, D.O. A Educação à Distância e a função do professor. Id on Line Revista Multidisciplinar e de Psicologia, Janeiro de 2017, vol.10, n.33, p. 320-329. ISSN: 1981-1179.

Recebido: 06/12/2016

Aceito: $08 / 12 / 2016$ 